\title{
Palatal rugoscopy: Individuality and gender differences in subset of population of Karachi.
}

\footnotetext{
1. BDS

Senior Lecturar Oral Biology Dow Dental College, Karachi.

2. BDS

Senior Lecturar Oral Biology Sir Syed College of Dentistry, Karachi.

3. BDS, M.Phil Associate Professor Oral Biology Dow Dental College, Karachi.

4. BDS

Senior Lecturar Oral Biology Dow Dental College, Karachi.

5. BDS, MCPS

Associate Professor Oral Biology Isra Dental College, Karachi.

6. MD, MSc, MFDS, MFD, FAIMER Assistant Professor Oral Biology Dow Dental College, Karachi.
}

Correspondence Address:

Dr. Syed Jaffar Abbas Zaidi

House No. FL1/11, Block No.3,

Gulshan e lqbal Karachi.

jaffar.zaidi@duhs.edu.pk

Article received on:

02/07/2020

Accepted for publication:

05/11/2020
Sanam Faheem 1 , Suraiya Hirani' ${ }^{2}$, Shahida Maqsood ${ }^{3}$, Faheem Shaikh ${ }^{4}$, Maqsood Ahmed Soomro ${ }^{5}$, Syed Jaffar Abbas Zaidi 6

ABSTRACT... Objectives: To evaluate the individuality of palatal rugae patten and correlate them in males and females in different age groups by using Trobo's classification. Study Design: Cross Sectional. Setting: Department of Prosthodontics, Dow Dental College, Dow University of Health Sciences. Period: September 2019 to January 2020. Material \& Methods: This study comprised of ninety-four participants with equal number of males and females from 10 years to 70 years, visiting the Prosthodontic department. Study casts included were free of dental abnormality, trauma, malocclusion, orthodontic problems, and deformity in palatal rugae area. Sample size was calculated from software name openepi.com with $95 \%$ confidence interval. Data was tabulated and SPSS version 22.0 was used to identify the results. Results: Frequency distribution was performed among age groups in which second group (20 to 39 years) has highest frequency with 52 in number. The cross tab between age group and type of rugae was made which showed group II, having age between 20 to 39 years, had the highest number of palatal rugae configurations amongst all. Conclusion: Sinuous or type E was the predominant type of palatal rugae found in this study. The study did not show significant difference in gender, however number of rugae were found consistently more in young adults with propensity towards individuality. Their use can thus be justified for dental identification in forensic odontology.

Key words: $\quad$ Forensic Identification, Forensic Odontology, Oral Biology, Palatal Rugae, Palatal Rugoscopy.

Article Citation: Faheem S, Hirani S, Maqsood S, Shaikh F, Soomro MA, Zaidi SJA. Palatal Rugoscopy: Individuality and gender differences in subset of population of Karachi. Professional Med J 2021; 28(6):842-847. https://doi.org/10.29309/TPMJ/2021.28.06.5397

\section{INTRODUCTION}

Forensic identification is an important requirement of forensic sciences owing to the legal and social aspects. ${ }^{1}$ Extraction of DNA from human tooth or tissue, finger prints and marks of lips are different methods for accurate identification, but in the last few years Palatal rugae have also being considered for forensic identification. ${ }^{2}$ Rugae have many physiological functions, it not only helps in suction in children, but also aids in digestion like mastication and swallowing and also facilitates in speech. ${ }^{3}$ These are unique, asymmetrical and irregular mucosal elevations present on the anterior two third of palate extending laterally from incisive papilla. ${ }^{4}$ Rugae appear in 3rd month of intrauterine life and remain consistent throughout life, even after completion of growth, their position by lips, cheeks( buccal pad of fat) and teeth provides them a great protection by traumas and other postmortem insults. ${ }^{5,6}$ Differences in size, shape, number and position in every individual makes them an ideal tool for human identification. ${ }^{7}$ Hence can be used as an important parameter in forensic odontology because of its uniqueness, stability and resistance (to trauma, high temperatures, combustions), it also resists decomposition for seven days after death. ${ }^{7,8}$

Palatal rugae are also used in orthodontics as stable reference points for evaluate the movement of teeth by superimposing the casts. ${ }^{9}$ Furthermore, palatal rugae have been associated with different malocclusions due to stability and inherited characteristics of palatal rugae. Although it is a relatively stable anatomical landmark, but it 
is subject to changes related to digit sucking and orthodontic palatal expansion.

The characteristics of palatal rugae, their location and alignment and their relationship with incisive papilla and their forking with respect to the mid-palatal raphe are studied as an integral component of Oral Biology in undergraduate dental education in Pakistan. ${ }^{10}$

There are many classifications to study the patterns of Rugae. Lysell developed first classification in 1955. Other classifications are based either on morphology, size, shape, or number. Trobo divided them into simple and composed rugae presented by letters. ${ }^{11}$ Trobo's classification is unique that it comprehensively encompasses all possible shapes and configurations of the palatal rugae that are missed by other classifications. Composed rugae is made by union of two or more simple rugae. Simple rugae are classified from letters $A$ to $F$ and composed with letter $X .{ }^{12}$

Many researches have been conducted to study the pattern differences of palatal rugae between male and female by other classifications but they lack uniformity, comprehensiveness and userfriendliness. ${ }^{5,6,8,11}$

There is a paucity of local studies evaluating the uniqueness and gender differences of palatal rugae using Trobo's classification for use in forensic dentistry and as a diagnostic appurtenance.

The objective of this study was to evaluate the patterns of palatal rugae in males and females in differentage groups by using Trobo's classification and correlate any gender differences with the patterns of palatal rugae.

\section{MATERIAL \& METHODS}

This cross-sectional study comprised of patient's cast aged from 10 years to 70 years, coming to Prosthodontic department of Dow Dental College for the period of 5 months from September 2019 to January 2020. Only those patients were included who consented for this study. This non-invasive study was conducted in commonly accepted educational settings and was in accordance with ethical standards of Helsinki Declaration. Informed consent was obtained from all the participants and anonymity and confidentiality of participants was guaranteed.

All the impressions and casts were taken for routine treatment at the Prosthodontic department for replacement of their teeth. Only those study casts were included in the study that were free of air bubbles, specifically from anterior third portion of palate where palatal rugae are present. Study cast included were free of dental abnormality, trauma, malocclusion, orthodontic problems, and deformity in palatal rugae area. Sample size was calculated from Openepi.com with 95\% confidence interval.

The rugae pattern were outlined using sharp pencil under suitable light on basis of their shape using Trobo's classification (Figure-1) by principal investigators. Each type of rugae was color coded to identify it.

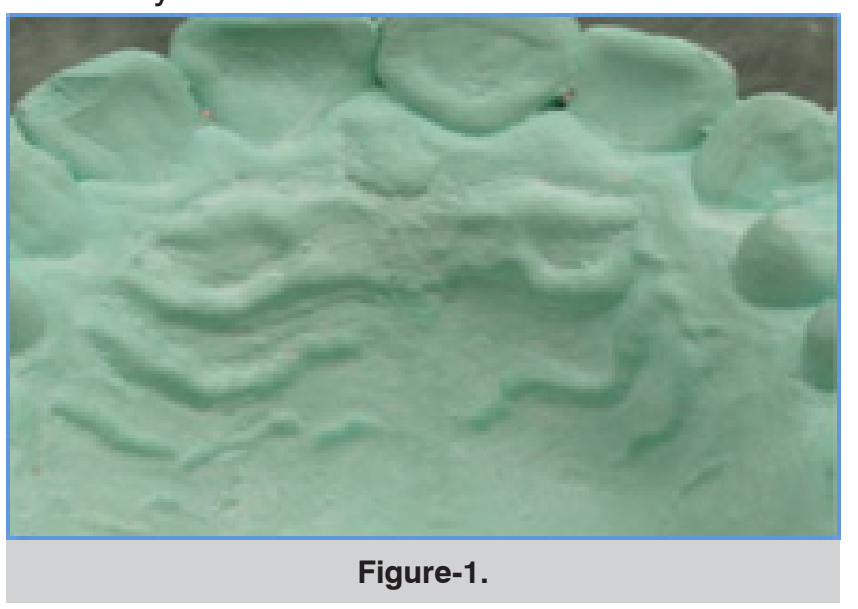

Data was tabulated and SPSS version 22.0 was used to identify the results. Frequency, distribution of gender and age groups were calculated and cross tab between gender and age group with type of rugae were calculated. T-test was applied to evaluate significant results of gender with type of rugae.

\section{RESULTS}

Total ninety-four participants participated in the study with equal numbers of males and females (Table-I). 


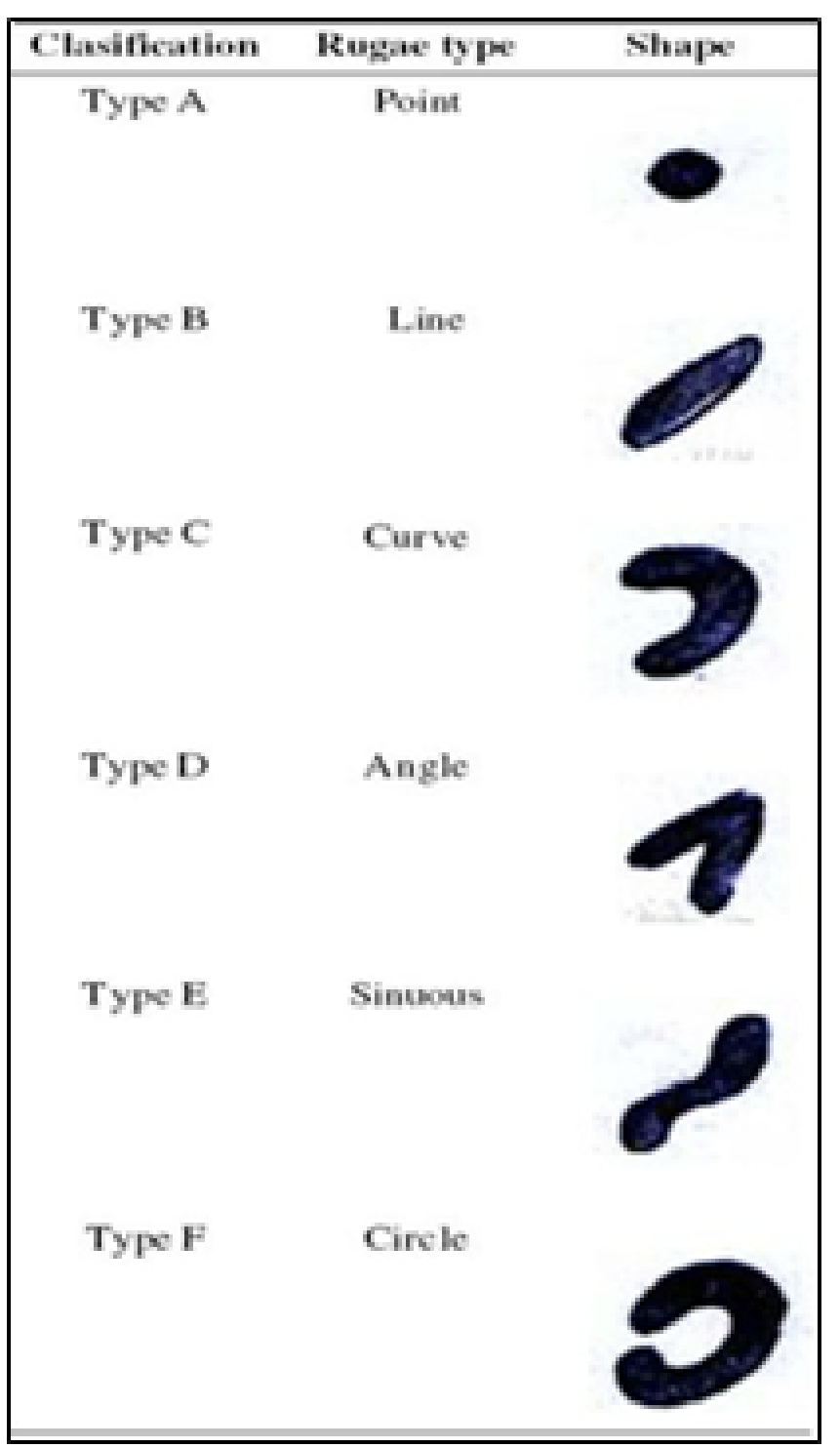

Figure-2. Trobo's classification.

\begin{tabular}{|l|c|c|}
\hline Type of Rugae & Name of Type & Color Code \\
\hline Type a & Point & Dark green \\
\hline Type b & Line & Red \\
\hline Type c & Curve & Dark purple \\
\hline Type d & Angle & Dark blue \\
\hline Type e & Sinuous & Blue \\
\hline Type f & Circle & Grey \\
\hline
\end{tabular}

Figure-3. Color coding according to classification.

\begin{tabular}{|l|c|}
\hline \multicolumn{1}{|c|}{ Gender } & Frequency \\
\hline Male & 47 \\
\hline Female & 47 \\
\hline Total & 94 \\
\hline
\end{tabular}

Table-I. Frequency distribution of males and females.

Total number of rugae was counted and crosstab was made between gender and type of rugae which does not show significant total number of rugae in both the genders. Palatal rugae type $\mathrm{E}$ (sinuous) and type B (line) displayed highest numbers with occurrence of 93 and 89 respectively, in total study population (Table-II).

T-test was applied concerning gender and type of rugae which did not show statistically significant difference in the P-values (Table-III).

Frequency distribution was done amongst all age groups. Group II with 20 to 39 years of age had highest frequency with 52 in number (Table-IV).

The cross tab between age group and type of rugae was made which showed group 2, having age between 20 to 39 years, highest number of palatal rugae in all (Table-V).

\section{DISCUSSION}

No two individuals have the same palatal rugae pattern. ${ }^{7}$ Owing to its uniqueness, individuality, stability, the patterns of palatal rugae and their configurations are studied through non-invasive means such as palatal rugoscopy and other complex, expensive and technique sensitive methods like calcorrugoscopy, stereoscopy, and stereophotogrammetry that are complex and expensive. ${ }^{13}$ The most economical and simplest technique used for study of palatal rugae is to study with maxillary cast models. ${ }^{1}$ Palatal rugae are classified on the basis of length, pattern, and shape.

\begin{tabular}{|c|c|c|c|c|c|c|c|}
\hline \multirow[t]{2}{*}{ Gender } & \multicolumn{6}{|c|}{ Type of Palatal Ruage } & \multirow[t]{2}{*}{ Total } \\
\hline & A & B & C & D & $\mathbf{E}$ & $\mathbf{F}$ & \\
\hline Male & 2 & 45 & 12 & 4 & 46 & 18 & 127 \\
\hline Total & 4 & 89 & 24 & 8 & 93 & 36 & 254 \\
\hline
\end{tabular}




\begin{tabular}{|c|c|c|c|}
\hline Type of Rugae & Gender & MEAN \pm SD & P-Value \\
\hline A & Male & $0.13 \pm 0.741$ & 0.589 \\
\hline \multirow{2}{*}{ B } & Female & $0.06 \pm 0.323$ & 0.374 \\
\hline C & Male & $1.89 \pm 1.355$ & 0.615 \\
\hline D & Female & $2.15 \pm 1.414$ & \multirow{2}{*}{1.000} \\
\hline \multirow{2}{*}{ E } & Male & $0.36 \pm 0.6673$ & 0.104 \\
\hline \multirow{2}{*}{ F } & Female & $0.30 \pm 0.548$ & $0.09 \pm 0.282$ \\
\end{tabular}

Table-III. T-test between gender and type of rugae.

\begin{tabular}{|l|c|}
\hline \multicolumn{1}{|c|}{ Age Group } & Frequency \\
\hline Group 1 (09-19 Years) & 10 \\
\hline Group 2 (20-39 Years) & 52 \\
\hline Group 3 (40-59 Years) & 22 \\
\hline Group 4 (60-79 Years) & 10 \\
\hline Total & 94 \\
\hline
\end{tabular}

Table-IV. Frequency distribution of age groups.

\section{Age Group}

GROUP 1 (09-19 YEARS)

GROUP 2 (20-39 YEARS)

GROUP 3 (40-59 YEARS)

GROUP 4 (60-79 YEARS)

TOTAL

\section{Type of Rugae}

\begin{tabular}{|c|c|}
\hline B & C \\
\hline 8 & 1 \\
\hline 50 & 17 \\
\hline 22 & 5 \\
\hline 9 & 1 \\
\hline 89 & 2 \\
\hline
\end{tabular}

\begin{tabular}{|c|c|}
\hline C & \\
\hline 1 & \\
\hline 17 & \\
\hline 5 & \\
\hline 1 & \\
\hline 24 & \\
\hline
\end{tabular}

Total

Table-V. Crosstab between age groups and type of palatal rugae.

Numerous classifications have been proposed by many authors among which the most acceptable classification was given in 1983 by Thomas and Kotze. As Trobo was the first one who suggest to study palatal rugae with respect to its shape and introduced the concept of "Palatal Rugoscopy" in 1932 therefore Trobo's classification of palatal rugae was used in this study due to its, user-friendliness, comprehensiveness and uniqueness. ${ }^{4}$

Once palatal rugae are formed; they only change in their length with the growth of the palate. The shape of the rugae remains constant and this stability of palatal rugae pattern has implication for its potential use in forensic dentistry when personal identification cannot be achieved by other methods. It is important to note the presence of abnormal palatal rugae that indicate alterations in growth of rugae. ${ }^{14}$ Change in shape of rugae can be due to any deleterious parafunctional habits such as finger sucking or due to excessive pressure from orthodontic treatment. ${ }^{2,3,11}$ Comparison between genders was done on different population samples internationally and nationally thus this study aimed to evaluate shape of palatal rugae with respect to gender as well as age groups. ${ }^{9}$ A study was conducted in 2016 which did not show any significant difference of numbers of palatal rugae between males and females. ${ }^{15}$ This study also did not show any difference in number of palatal rugae between males and females. 
The most common and predominant configuration of palatal rugae found was sinuous followed by line with point being the least common one as observed in other studies done previously. ${ }^{3}$ These findings could be attributed to racial and ethnic differences and can be used to establish individuality and uniqueness of palatal rugae pattern.

Fawzi et al. reported palatal rugae difference when compared to genders whereas no such difference was established in this study. ${ }^{11}$ Mostly studies were done to establish difference of shape, direction, and length of rugae between sexes. ${ }^{2,5,6,8,11,14}$ Altayeb et al. did not endorse palatal rugae alteration among males and females ${ }^{16}$ which supported the results of the present study. Both males and females have similar rugae pattern with respect to shape in this study, when these shape of rugae were compared in different age groups they presented highest numbers in age group between 20 to 39 years. This may indicate that palatal rugae are usually shrunk in older ages due to wearing of dentures. ${ }^{17}$

Due to the uniqueness and stability of palatal rugae pattern, dental records and specifically dental casts should routinely be stored by dentists so that antemortem and postmortem records could be matched for forensic identification purposes. ${ }^{18}$

There is a dire need to create awareness amongst the judiciary and the police department regarding potential of palatal rugae pattern analysis and in mass disasters such as plane crashes, road traffic accidents, train accidents and natural calamities for identification of individuals. ${ }^{15,17}$

\section{CONCLUSION}

Type-E (sinuous) was the most predominant palatal rugae found in our study depicting individuality and racial differences. Although, the present study did not show significant difference in gender, however number of rugae were more in young adult ages .Large scale multi-center studies are recommended on larger samples to establish individuality, racial and ethnic differences based on palatal rugae pattern amongst the Pakistani population.
Copyright $(05$ Nov, 2020.

\section{REFRENCES}

1. Jindal V, Mahajan A, Mahajan N, Goel A, Kaur R, Puri C. Rugae pattern determination in periodontitis patients: A descriptive study. Journal of the International Clinical Dental Research Organization. 2016; 8(2):115.

2. Buyuk SK, Simsek H, Yasa Y, Genc E, Turken R. Morphological assessment of palatal rugae pattern in a Turkish subpopulation. Australian Journal of Forensic Sciences. 2019; 51(1):40-8.

3. Barbo BN, Azeredo F, Menezes L. Assessment of size, shape, and position of palatal rugae: A Preliminary Study. Oral Health and Dental Studies. 2018; 1(1):3.

4. Selvamani M, Bindiya P, Bhojaraju N, Bastian T, Suhana $\mathrm{H}$, Mathew $M$. Morphological analysis of various rugae patterns among dravidian population. Journal of oral and maxillofacial pathology: JOMFP. 2019; 23(2):295.

5. Pappu BT, Gopinathan TA, Naduvakattu B. Assessment of different palatal rugae patterns in gender identification. International Journal of Oral Care and Research. 2018; 6(3):17.

6. Pakshir F, Ajami S, Pakshir HR, Malekzadeh AR. Characteristics of palatal rugae patterns as a potential tool for sex discrimination in a sample of Iranian children. Journal of Dentistry. 2019; 20(1):1.

7. Setiadi D, Syukriani YF, Supian S, Oscandar F, Malinda $\mathrm{Y}$, Nugraha A. Association between direction patterns of palatal rugae and thumbprints: Implications for forensic identification. Journal of Dentistry Indonesia. 2019; $26(1): 4$.

8. Gadicherla P, Saini D, Bhaskar M. Palatal rugae pattern: An aid for sex identification. Journal of forensic dental sciences. 2017; 9(1):48.

9. Kapoor P, Kaur R, Kaur H. Rugoscopy: A diagnostic appurtenance for malocclusion or just a forensic aid?-a pilot study. Journal of Forensic Research. 2015; 6(2):1.

10. Ansari AS, Shaikh AT, Zaidi SJA, Ansari ZM, Kazmi S. Permanent mandibular second molars; occlusal morphological characteristics of permanent mandibular second molars in a sample of Pakistani population. Professional Medical Journal. 2018; 25(11).

11. Fawzi M, Eldomiaty M, Desouky M, Algaidi S. Evaluation of the role of palatal rugae application as a tool for sex identification in the Saudi population. WIMJ Open. 2016; 3(1):28-31. 
12. Bhayana G, Kumar A, Atreja SH, Atreja G, Juneja A. Palatoscopy: A novel tool in human identification. American Journal of Oral Medicine and Radiology. 2016; 3(1):01-6.

13. V N, Ugrappa S, M NJ, Ch L, Maloth KN, Kodangal S. Cheiloscopy, palatoscopy and odontometrics in sex prediction and dis-crimination - a comparative study. Open Dent J. 2014; 8:269-79.

14. Gondivkar SM, Patel S, Gadbail AR, Gaikwad RN, Chole $\mathrm{R}$, Parikh RV. Morphological study of the palatal rugae in western Indian population. Journal of forensic and legal medicine. 2011; 18(7):310-2.
15. Amjad A, Hussain S, Rehman A, Hassan SH. Role of palatal rugae pattern in forensic identification of individuals. Pakistan Orthodontic Journal. 2016; 8(2):104-8.

16. Ahmed AA, Hamid A. Morphological study of palatal rugae in a sudanese population. International journal of dentistry. 2015; 2015.

17. Caldas IM, Magalhaes T, Afonso A. Establishing identity using cheiloscopy and palatoscopy. Forensic science international. 2007; 165(1):1-9.

18. Bowers $\mathrm{CM}$. Jurisprudence issues in forensic odontology. Dent Clin North Am. 2001; 45(2):399-415, ix.

\begin{tabular}{|c|l|l|l|}
\hline \multicolumn{3}{|c}{ AUTHORSHIP AND CONTRIBUTION DECLARATION } \\
\hline Sr. \# & \multicolumn{1}{|c|}{ Author(s) Full Name } & \multicolumn{1}{|c|}{ Contribution to the paper } & Author(s) Signature \\
\hline 1 & Sanam Faheem & $\begin{array}{l}\text { Conceptualization of study } \\
\text { design. } \\
\text { Data collection \& } \\
\text { reading. Proof } \\
\text { Write up and literature search. }\end{array}$ \\
\hline 3 & Suraiya Hirani & Shahida Maqsood & $\begin{array}{l}\text { Data analysis and } \\
\text { collection. Data } \\
\text { Data interpretation. }\end{array}$ \\
\hline 5 & Syed Jaffar Abbas Zaidi & $\begin{array}{l}\text { Spdated references, Proof } \\
\text { reading and formatting. }\end{array}$ \\
\hline
\end{tabular}

